\title{
Biochemical and computational insights into the anti-aromatase activity of natural catechol estrogens
}

\author{
Marco A.C. Neves ${ }^{a}$, Teresa C.P. Dinis ${ }^{b}$, Giorgio Colombo ${ }^{c}$, M. Luisa Sá e Melo ${ }^{a}{ }^{*}$ \\ ${ }^{a}$ Centro de Estudos Farmacêuticos, Lab. Química Farmacêutica, Faculdade de Farmácia, Universidade de Coimbra, \\ 3000-295 Coimbra, Portugal \\ ${ }^{\mathrm{b}}$ Centro de Neurociências, Universidade de Coimbra, Lab. Bioquímica, Faculdade de Farmácia, Universidade de Coimbra, \\ 3000-295 Coimbra, Portugal \\ ${ }^{\mathrm{c}}$ Istituto di Chimica del Riconoscimento Molecolare, CNR, 20131 Milano, Italy
}

Received 2 April 2007; accepted 19 October 2007

\begin{abstract}
High levels of endogenous estrogens are associated with increased risks of breast cancer. Estrogen levels are mainly increased by the activity of the aromatase enzyme and reduced by oxidative/conjugative metabolic pathways. In this paper, we demonstrate for the first time that catechol estrogen metabolites are potent aromatase inhibitors, thus establishing a link between aromatase activity and the processes involved in estrogen metabolism. In particular, the anti-aromatase activity of a set of natural hydroxyl and methoxyl estrogen metabolites was investigated using biochemical methods and subsequently compared with the anti-aromatase potency of estradiol and two reference aromatase inhibitors. Catechol estrogens proved to be strong inhibitors with an anti-aromatase potency two orders of magnitude higher than estradiol. A competitive inhibition mechanism was found for the most potent molecule, 2-hydroxyestradiol $\left(2-\mathrm{OHE}_{2}\right)$ and a rational model identifying the interaction determinants of the metabolites with the enzyme is proposed based on $a b$ initio quantum-mechanical calculations. A strong relationship between activity and electrostatic properties was found for catechol estrogens. Moreover, our results suggest that natural catechol estrogens may be involved in the control mechanisms of estrogen production.
\end{abstract}

(c) 2008 Elsevier Ltd. All rights reserved.

Keywords: Breast cancer; Aromatase inhibition; Estradiol metabolites; Catechol estrogens; Structure-activity relationships; Electrostatic surface potential

\section{Introduction}

Estrogens are important for the normal development and growth of the human body. Besides their involvement in sexual differentiation, control of the reproductive cycle and pregnancy, they are implicated in many non-reproductive functions. For instance, in the cardiovascular system, estrogens have protective effects either directly through the interaction with the blood vessels or indirectly through the plasma lipoprotein metabolism [1]. In the bone, estrogens regulate the normal mineralization, controlling the balance between bone formation and bone resorption [2]. In the central nervous system, several neuroendocrine functions have been attributed to estrogens, namely the neuroprotection against Alzheimer's disease and schizophrenia [3].

\footnotetext{
* Corresponding author. Tel.: +351 239859990; fax: +351 239827030.

E-mail address: samelo@ff.uc.pt (M. Luisa Sá e Melo).
}

However, prolonged exposure to high concentrations of estrogens might have detrimental effects. Breast and uterus are highly sensitive to the mitogenic effects of estrogens and an excessive cell proliferation can lead to replication errors and to an increased risk of breast and endometrial cancer [4].

Estrogens are metabolized by oxidative and conjugative pathways. Cytochrome P450 (CYP), a superfamily of metabolizing enzymes, produces mostly A-ring metabolites, by 2 - and 4hydroxylation, and D-ring metabolites by $16 \alpha$-hydroxylation [5] (Fig. 1). The catechol metabolites are converted by catechol- $O$-methyltransferase (COMT) to their 2-methoxy and 4-methoxyestrogen metabolites and subsequently to their glucuronide, sulfate and glutathione conjugates. These more soluble metabolites are found in large amounts in the urine.

Although initially considered inactive, estradiol metabolites (Fig. 1) have gained interest in recent years due to the discovery of pro and anticarcinogenic activities and to the elucidation of their potential to bind to the estrogen receptor and to have estrogenic activity. 2-Hydroxyestradiol $\left(2-\mathrm{OHE}_{2}, \mathbf{6}\right)$ is the major 


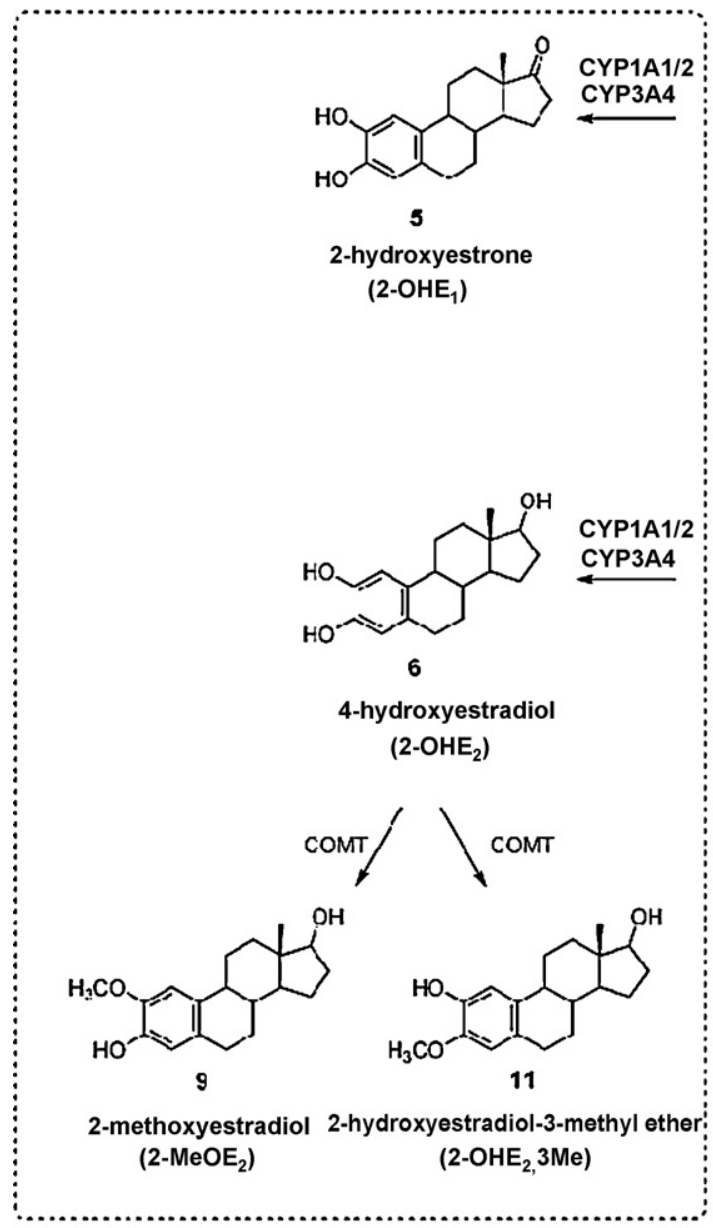

C2 metabolites

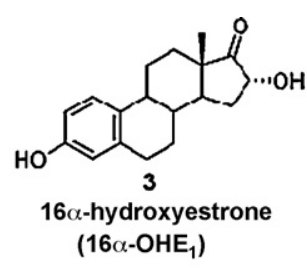<smiles>CC(C)(C)CC1CCC2C(C1)c1ccc(O)cc1CC1C(=O)CCC12</smiles>

$\left(E_{1}\right)$

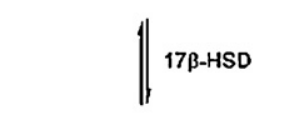<smiles>CC(C)(C)[C@H]1CCC2C(CCC3C(O)CCC32)c2ccc(O)cc21</smiles>

$\left(E_{2}\right)$

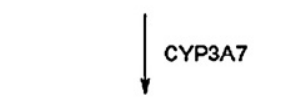<smiles>C[C@@H]1CC2C(CCC3C2C[C@H](O)C3O)c2ccc(O)cc21</smiles>

16 $\alpha$-hydroxyestradiol $\left(E_{3}\right)$<smiles></smiles>

4-hydroxyestrone $\left(4-\mathrm{OHE}_{1}\right)$

CYP1B1

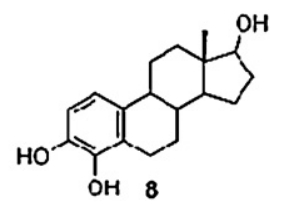

4-hydroxyestradiol $\left(4-\mathrm{OHE}_{2}\right)$<smiles>[TeH][TeH]</smiles>

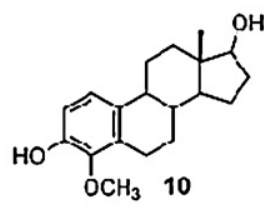

4-methoxyestradiol

$\left(4-\mathrm{MeOE}_{2}\right)$

C4 metabolites

Fig. 1. Schematic representation of estrogen conversion paths.

metabolite formed by CYP hydroxylation at the liver and has much weaker estrogenic activity than the parent hormone estradiol $\left(\mathrm{E}_{2}, \mathbf{1}\right)$ [6]. 4-Hydroxyestradiol $\left(4-\mathrm{OHE}_{2}, \mathbf{8}\right)$ is produced in a minor pathway and has an estrogenic activity similar to estradiol. Both these catechol estrogens can undergo metabolic redox cycling with generation of reactive intermediates like quinones/semiquinones and free radicals which can damage biological macromolecules [7]. This mechanism has been pointed out to explain the carcinogenic activity of estrogens. Interestingly, in vivo studies have demonstrated that $2-\mathrm{OHE}_{2}$ does not induce tumors, in contrast to $4-\mathrm{OHE}_{2}$ which is a potent carcinogen [8]. 2-Hydroxyestrone $\left(2-\mathrm{OHE}_{1}, \mathbf{5}\right)$ was found to have antiestrogenic activity in the hormone-dependent human breast cancer cell line MCF-7 [9] and 2-methoxyestradiol (2-MeOE 2 ,
9) was found to be antiangiogenic and antiproliferative in several tumor types [10] and almost devoid of estrogenic activity.

In a similar manner to the 4-hydroxyl metabolites, the $16 \alpha-$ hydroxyl estrogens (Fig. 1, compounds 3 and $\mathbf{4}$ ) retain strong hormonal potency [11] and were suggested to increase the risk of developing breast cancer $[12,13]$. Therefore, despite the oxidative and conjugative metabolism, estrogen derivatives carry out several biological activities beyond the estrogenic activity of estradiol.

Aromatase is the cytochrome $\mathrm{P} 450$ enzyme responsible for the production of estrogens from the corresponding androgens [14]. Recent advances in breast cancer therapy have been achieved with the use of aromatase inhibitors [15] such as anastrozole and letrozole $[16,17]$. Shimizu et al. showed that natural 
estrogens, like estradiol and estrone, are able to bind to the active site of the human placental aromatase as competitive inhibitors [18]. These molecules are remarkably different from the known inhibitors, which makes them attractive because of their potential for lead optimization towards better therapeutical prospects. Furthermore, since estrogens are produced endogenously, an in situ mechanism of aromatase activity regulation might occur. However, the preliminary study performed by those researchers was not further extended to the catechol estrogen metabolites and their methoxy derivatives.

In this paper, we have focused on the biochemical evaluation of the anti-aromatase potential of a set of natural hydroxyl and methoxyl estradiol/estrone metabolites and a related synthetic derivative, the 2-methoxyestradiol-3-methylether (Fig. 4, compound 12), using an in vitro assay with aromatase extracted from human term placenta. Catechol estrogens proved to be strong inhibitors with an anti-aromatase potency two orders of magnitude higher than estradiol. A competitive inhibition mechanism was found for the most potent molecule, 2-OHE 2 (Fig. 1, compound 6). Furthermore, a rationale for the molecular interaction is proposed based on ab initio quantum chemical methods.

\section{Materials and methods}

\subsection{Materials}

Estradiol, 2-hydroxyestradiol, 2-methoxyestradiol, 2hydroxyestradiol-3-methyl ether, 2-methoxyestradiol-3-methyl ether, 4-hydroxyestradiol, 4-methoxyestradiol, 16 $\alpha$ hydroxyestradiol, estrone, 2-hydroxyestrone, 4-hydroxyestrone and $16 \alpha$-hydroxyestrone were purchased from Steraloids, Inc. (London, UK). Formestane, NADPH and DL-aminoglutethimide were purchased from Sigma-Aldrich (St. Louis, MO, U.S.A.). $\left[1 \beta-{ }^{3} \mathrm{H}\right]$ Androstenedione (specific activity $25.3 \mathrm{Ci} / \mathrm{mmol}$ ) and the liquid scintillation cocktail Optiphase Hisafe 2 were purchased from PerkinElmer (Boston, MA, U.S.A.). All the other reagents were of adequate grade for biochemical analysis.

\subsection{Enzymatic preparation}

Microsomes from human term placenta were obtained according to the method described by Ryan [19] and were used as the source of the enzyme. Briefly, the placenta was washed with saline solution, removed from large blood vessels and connective tissues, and homogenized in a buffer containing $0.05 \mathrm{M}$ sodium phosphate, $\mathrm{pH} 7.0,0.25 \mathrm{M}$ sucrose and $0.04 \mathrm{M}$ nicotinamide. Then, a microsomal preparation was isolated by a differential centrifugation procedure with the final centrifugation at $105,000 \times g$ for $1 \mathrm{~h}$. The microsomes were resuspended in a medium containing $0.1 \mathrm{M}$ sodium phosphate, $\mathrm{pH} 7.4,0.25 \mathrm{M}$ sucrose, $20 \%$ glycerol and $0.5 \mathrm{mM}$ dithiothreitol and stored in aliquots at $-80^{\circ} \mathrm{C}$ until needed. All procedures were carried out at $4^{\circ} \mathrm{C}$. No significant loss of activity occurred during the time required to complete the assays.

Microsomal protein content was determined by the biuret method using bovine serum albumin as standard.

\subsection{Concentration-response study}

Aromatase activity was measured by quantifying the amount of ${ }^{3} \mathrm{H}_{2} \mathrm{O}$ released when the enzyme converts the tritiated substrate, $\left[1 \beta-{ }^{3} \mathrm{H}\right]$ androstenedione, to the corresponding estrogen. This method was first described by Siiteri and Thompson [20]. Incubations were performed at $37^{\circ} \mathrm{C}$ in a medium containing $67 \mathrm{mM}$ sodium phosphate, $\mathrm{pH} 7.5,\left[1 \beta-{ }^{3} \mathrm{H}\right]$ androstenedione $\left(6.6 \times 10^{5} \mathrm{dpm} / 24 \mathrm{nM}\right), 15 \mu \mathrm{l}$ methanol and $270 \mu \mathrm{M}$ NADPH. The potential inhibitors were dissolved in DMSO and added to the assay in concentrations ranging from 31.62 to $640 \times 10^{3} \mathrm{nM}$. The amount of DMSO in the assay was always equal to $2 \%$ and the final incubation volume was $500 \mu \mathrm{L}$. The reaction was started with the addition of $30 \mu \mathrm{g}$ of microsomal protein and stopped after $20 \mathrm{~min}$ by adding $1 \mathrm{~mL}$ of chloroform and vortexing at $9000 \mathrm{rpm}$ for $40 \mathrm{~s}$. After centrifugation at $3000 \mathrm{rpm}$ for $5 \mathrm{~min}$, the organic phase was discarded and the extraction procedure was repeated. An aliquot $(250 \mu \mathrm{L})$ of the aqueous layer was collected and mixed with $3 \mathrm{~mL}$ of liquid scintillation cocktail. The amount of tritiated water formed in each assay was determined in a Packard Tri-Carb 2000 CA Liquid Scintillation Analyzer. Appropriate controls without the compounds in study were performed in order to determine the maximum enzymatic activity to which the relative percentage of inhibition was determined. Results were expressed as mean \pm S.E.M. of three independent assays, each one in triplicate. Data were treated by nonlinear regression analysis, using a sigmoidal concentration-response curve with variable slope. GraphPad Prism software, version 4.00 was used for this purpose.

\subsection{Kinetic analysis}

For the kinetic study, similar conditions to the concentration-response study were used. The concentration of $\left[1 \beta^{-3} \mathrm{H}\right]$ androstenedione was varied from 25 to $300 \mathrm{nM}$, the concentrations of 2-hydroxyestradiol tested were 500, 1000 and $1500 \mathrm{nM}$ and the reaction time was $5 \mathrm{~min}$. An assay without inhibitor was also performed. Results were expressed as mean \pm S.E.M. of at least three independent assays, each one in duplicate. Data were fitted by nonlinear regression to the Michaelis-Menten equation. The kinetic constants, $V_{\max }, K_{\mathrm{m}}$ and $K_{\mathrm{i}}$ were estimated by nonlinear curve fitting, and the type of inhibition was determined from Lineweaver-Burk plots. GraphPad Prism software, version 4.00 was used for this purpose.

\subsection{Electrostatic surface potential calculation details}

Three-dimensional models of all molecules were constructed using building fragments from the standard libraries of MAESTRO 5.1.016 (Schrödinger). Initial geometry optimization was performed with a conformational search following the Systematic Unbounded Multiple Minimum (SUMM) [21] routine implemented in MACROMODEL 8.1 (Schrödinger) with the Merck Molecular Force Field (MMFFs) [22] and the PolakRibiere Conjugate Gradient (PRCG) minimization method with an energy convergence criterion of $0.05 \mathrm{~kJ} / \mathrm{mol}$. The Generalized Born equation/surface area (GB/SA) [23] continuum solvation 
model was used with parameters for water, with a dielectric constant $\varepsilon$ of 78. The molecular mechanics geometry was further optimized with Gaussian 98 (Gaussian, Inc.) [24] at the semiempirical Austin Model 1 (AM1) level and the electron density distribution for electrostatic surface potential (ESP) calculation was calculated at the HF/6-31G* level.

\section{Results}

\subsection{Concentration-response study}

Inhibition of the human placental aromatase by estradiol $\left(\mathrm{E}_{2}\right.$, 1), estrone $\left(\mathrm{E}_{1}, 2\right)$, their physiological metabolites $16 \alpha-\mathrm{OHE}_{1}$ (3), $\mathrm{E}_{3}(\mathbf{4}), 2-\mathrm{OHE}_{1}(\mathbf{5}), 2-\mathrm{OHE}_{2}(\mathbf{6}), 4-\mathrm{OHE}_{1}$ (7), 4-OHE 2 (8) 2- $\mathrm{MeOE}_{2}$ (9), 4- $\mathrm{MeOE}_{2}$ (10), 2-OHE, $3 \mathrm{Me}$ (11) (Fig. 1), and the related synthetic derivative $2-\mathrm{MeOE}_{2}, 3 \mathrm{Me}(\mathbf{1 2})$, was evaluated using an in vitro radiometric assay. Briefly, the use of a radiolabeled androgen as the substrate of the enzyme allowed a simple and rigorous quantification of the extent of the aromatization reaction which is proportional to the amount of tritiated water formed together with the corresponding estrogen. Full concentration-response curves were obtained by evaluation of the aromatase activity in the presence of the potential inhibitors with the maximal activity being given by control experiments (i.e. experiments without the compounds in study). A broad range of inhibitor concentrations to allow the determination of the half maximal inhibitory concentrations $\left(\mathrm{IC}_{50}\right)$ was used. In the case of less active compounds, low solubility at higher concentrations did not allow the establishment of a complete concentration-response curve. The $\mathrm{IC}_{50}$ and the percentage of aromatase inhibition at $100 \mu \mathrm{M}$ for the complete set of estrogens tested are shown in Table 1. The most active estrogens, $2-\mathrm{OHE}_{1}$ (5), 2-OHE 2 (6), 4-OHE 1 (7) and 4-OHE 2 (8) inhibited the aromatase enzyme with remarkable potency, showing a clear sigmoidal concentration-response behavior, as represented for compound 7 in Fig. 2. The observed potency is stronger than for the reference non-steroid first generation aromatase inhibitor tested, aminoglutethimide. In contrast, $\mathrm{E}_{2}(\mathbf{1}), \mathrm{E}_{1}(\mathbf{2})$ and their methoxy- and 16 $\alpha$-hydroxy derivatives showed lower anti-aromatase potency, as evidenced in Fig. 2 for $2-\mathrm{OHE}_{2}, 3 \mathrm{Me}$ (12) and $16 \alpha-\mathrm{OHE}_{1}(3)$. However, all the compounds in study presented a lower potency than formestane, a second generation steroid aromatase inhibitor, also used as a reference inhibitor (Table 1).

\subsection{Kinetic analysis}

A more detailed analysis on $2-\mathrm{OHE}_{2}(\mathbf{6})$, the most potent compound under study (lowest $\mathrm{IC}_{50}$ ), showed a mechanism of competitive inhibition, as displayed in the Lineweaver-Burk plot
Table 1

In vitro aromatase inhibition by estradiol, estrone and derivatives

\begin{tabular}{lll}
\hline Compound & $\mathrm{IC}_{50}(\mu \mathrm{M})^{\mathrm{a}}$ & Inhibition at $100 \mu \mathrm{M}(\%)$ \\
\hline $\mathrm{E}_{2}(\mathbf{1})$ & $227 \pm 8.3$ & 35 \\
$\mathrm{E}_{1}(\mathbf{2})$ & $36 \pm 1.0$ & 47 \\
$16 \alpha-\mathrm{OHE}_{1}(\mathbf{3})$ & $\mathrm{ND}^{\mathrm{b}}$ & 9 \\
$\mathrm{E}_{3}(\mathbf{4})$ & $\mathrm{ND}^{\mathrm{b}}$ & 8 \\
$2-\mathrm{OHE}_{1}(\mathbf{5})$ & $2.4 \pm 0.06$ & 94 \\
$2-\mathrm{OHE}_{2}(\mathbf{6})$ & $1.1 \pm 0.03$ & 95 \\
$4-\mathrm{OHE}_{1}(\mathbf{7})$ & $1.8 \pm 0.05$ & 96 \\
$4-\mathrm{OHE}_{2}(\mathbf{8})$ & $2.6 \pm 0.09$ & 92 \\
$2-\mathrm{MeOE}_{2}(\mathbf{9})$ & $296 \pm 10.2$ & 33 \\
$4-\mathrm{MeOE}_{2}(\mathbf{1 0})$ & $\mathrm{ND}$ & $14^{\mathrm{c}}$ \\
$2-\mathrm{OHE}_{2}, 3 \mathrm{Me}(\mathbf{1 1})$ & $134 \pm 1.8$ & 41 \\
$2-\mathrm{MeOE}_{2}, 3 \mathrm{Me}(\mathbf{1 2})$ & $234 \pm 3.0$ & 21 \\
Aminoglutethimide & $10 \pm 0.09$ & 92 \\
Formestane & $0.092 \pm 0.004$ & $\mathrm{ND}^{\mathrm{b}}$
\end{tabular}

${ }^{\text {a }}$ Results are shown as the mean \pm S.E.M. of three independent assays, each one in triplicate.

${ }^{b} \mathrm{ND}$ : not determined.

${ }^{c}$ Percentage of inhibition at $31.62 \mu \mathrm{M}$.

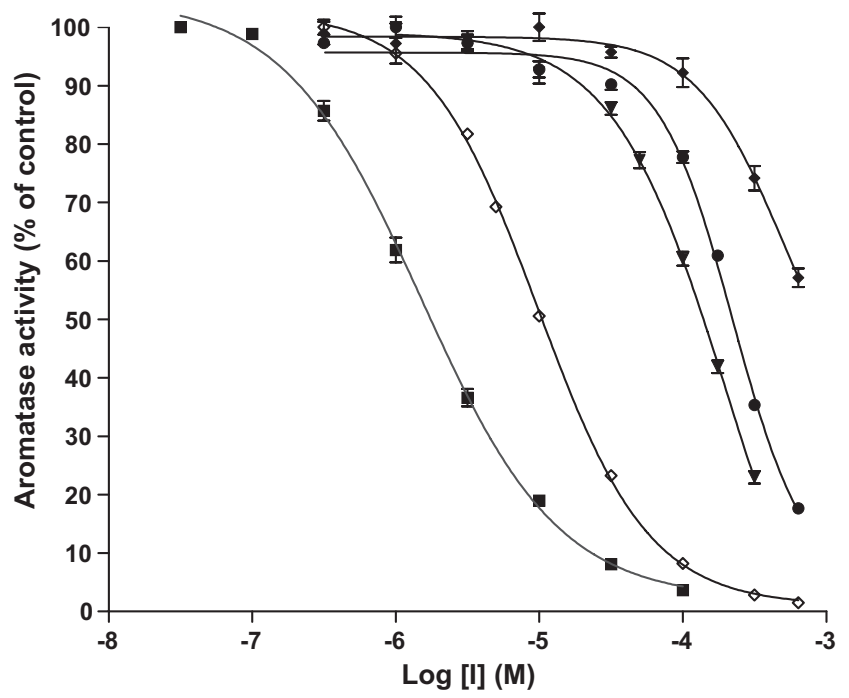

Fig. 2. Concentration-response curves obtained with 4- $\mathrm{OHE}_{1}$ (7) (ם), 2$\mathrm{OHE}_{2}, 3 \mathrm{Me}(\mathbf{1 1})(\mathbf{\nabla}), 2-\mathrm{MeOE}_{2}, 3 \mathrm{Me}(\mathbf{1 2})(\bullet)$ and $16 \alpha-\mathrm{OHE}_{1}(\mathbf{3})(\boldsymbol{})$ tested as aromatase inhibitors. Aminoglutethimide $(\diamond)$ was tested as a reference aromatase inhibitor. Each point represent the mean of three independent assays performed in triplicate and the vertical bars the standard error of the mean (S.E.M.). The data were analyzed by nonlinear regression analysis using a sigmoidal concentration-response curve with variable slope.

(Fig. 3). Experiments were performed with several concentrations of substrate in the absence and in the presence of three different concentrations of $2-\mathrm{OHE}_{2}(\mathbf{6})$. The data obtained were fitted by nonlinear regression to the Michaelis-Menten equation (Fig. 3, inset) and the kinetic constants are shown in Table 2.

Table 2

Kinetic constants $\left(K_{\mathrm{i}}, K_{\mathrm{m}}\right.$ and $\left.V_{\max }\right)$, relative inhibitory potency $\left(K_{\mathrm{i}} / K_{\mathrm{m}}\right)$ and type of aromatase inhibition by 2-OHE 2

\begin{tabular}{llllll}
\hline Compound & $K_{\mathrm{i}}(\mu \mathrm{M})^{\mathrm{a}}$ & $K_{\mathrm{m}}(\mu \mathrm{M})$ & $V_{\max }(\mathrm{pmol} / \mathrm{min} / \mathrm{mg}$ protein $)$ & $K_{\mathrm{i}} / K_{\mathrm{m}}$ & Inhibition \\
\hline $2-\mathrm{OHE}_{2}(\mathbf{6})$ & $1.6 \pm 0.03$ & $0.14 \pm 0.002$ & $70 \pm 0.5$ & 11 & Competitive \\
\hline
\end{tabular}

${ }^{a}$ Result is shown as the mean \pm S.E.M. of three independent assays, each one in duplicate. 


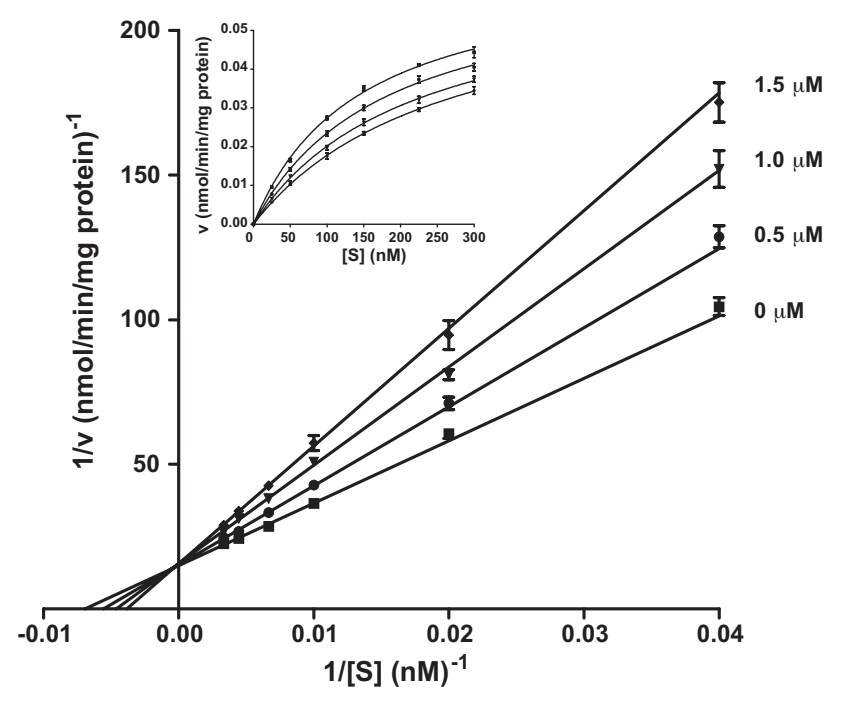

Fig. 3. Lineweaver-Burk plot of the inhibition of human placental aromatase by 2-OHE 2 (6). A control (ם) and three increasing inhibitor concentrations were used: $0.5 \mu \mathrm{M}(\mathbf{\odot}), 1.0 \mu \mathrm{M}(\boldsymbol{\nabla})$ and $1.5 \mu \mathrm{M}(\boldsymbol{\vee})$. A Michaelis-Menten plot of the same data is shown in the inset. Each point represents the mean of three independent assays performed in duplicate and the vertical bars, the standard error of the mean (S.E.M.).

\subsection{Electrostatic surface potential calculation}

Further understanding of the possible molecular recognition determinants leading to the binding of these catechol inhibitors to the active site of the aromatase, was pursued using $a b$ initio quantum chemistry methods. Six representative compounds, including the best inhibitor found in this study $\left(2-\mathrm{OHE}_{2}, 6\right)$, and five other related compounds, the estradiol precursor $\mathrm{E}_{2}$ (1), the 4-OHE 2 (8), a methoxy metabolite $\left(2-\mathrm{MeOE}_{2}, \mathbf{9}\right)$, the $2-\mathrm{MeOE}_{2}, 3 \mathrm{Me}(\mathbf{1 2})$ and a $16 \alpha$-hydroxyl derivative $\left(\mathrm{E}_{3}, \mathbf{4}\right)$, were represented in a three dimensional model with optimized geometry. The electrostatic potential derived from ab initio calculations at the Hartree-Fock theory level, along with the standard polarized $\zeta$ basis set $\left(\mathrm{HF} / 6-31 \mathrm{G}^{*}\right)$, mapped onto the electron density isosurface, is shown in Fig. 4. As expected, catechol estrogens, i.e. $2-\mathrm{OHE}_{2}(\mathbf{6})$ and $4-\mathrm{OHE}_{2}(\mathbf{8})$ have a strong negative electrostatic potential centered at each catechol oxygen atom, and are partially stabilized through an intramolecular hydrogen-bond. No steric hindrance limits the catechol access to a macromolecular target, therefore, intermolecular charge-transfer interactions might occur at the active site of the aromatase, either by hydrogen bonding or metal coordination, which might explain the strong anti-aromatase potency. Similar regions of negative electrostatic potentials are found in $2-\mathrm{MeOE}_{2}(\mathbf{9})$, however, substitution of the C2 hydroxyl by a methoxy group introduces sterical hindrance at the ring A and may limit the interaction with the enzyme, which might be responsible for the low anti-aromatase activity of $2-\mathrm{MeOE}_{2}(\mathbf{9})$. In a similar manner, $2-\mathrm{MeOE}_{2}, 3 \mathrm{Me}(\mathbf{1 2})$, a double methoxylated derivative, will fail to establish strong electrostatic interactions with the active site of the aromatase. On the other hand, $E_{2}(\mathbf{1})$ and $E_{3}(4)$, show a different ESP, with a single negative potential area derived from the 3-hydroxyl at the ring $\mathrm{A}$.

Electrostatic potential similarities between the two most active estrogens, $2-\mathrm{OHE}_{2}(\mathbf{6})$ and $4-\mathrm{OHE}_{2}(\mathbf{8})$, are clearly evident at the isosurface potential contour, represented in Fig. 5. The negative potential at ring A of both catechols is remarkably superimposable, either considering its spatial location or the intensity, suggesting a common binding mode, guided by strong electrostatic interactions.

\section{Discussion}

The biochemical evaluation of the main estradiol and estrone metabolites revealed that the catechol estrogens $2-\mathrm{OHE}_{1}(\mathbf{5}), 2-$ $\mathrm{OHE}_{2}(\mathbf{6}), 4-\mathrm{OHE}_{1}(\mathbf{7})$ and $4-\mathrm{OHE}_{2}(\mathbf{8})$ are potent aromatase inhibitors with half maximal inhibitory concentrations in the range of 1.1-2.6 $\mu \mathrm{M}$ (Table 1). In our assay conditions, $\mathrm{E}_{2}$ (1) showed anti-aromatase activity, though only at higher concentrations $\left(\mathrm{IC}_{50}=227 \mu \mathrm{M}\right)$. The substitution of one hydroxyl group at the catechol moiety by methoxy markedly decreased the anti-aromatase activity. In a similar manner, $2-\mathrm{MeOE}_{2}, 3 \mathrm{Me}$ (12), a 2,3-dimethoxy synthetic derivative, showed reduced

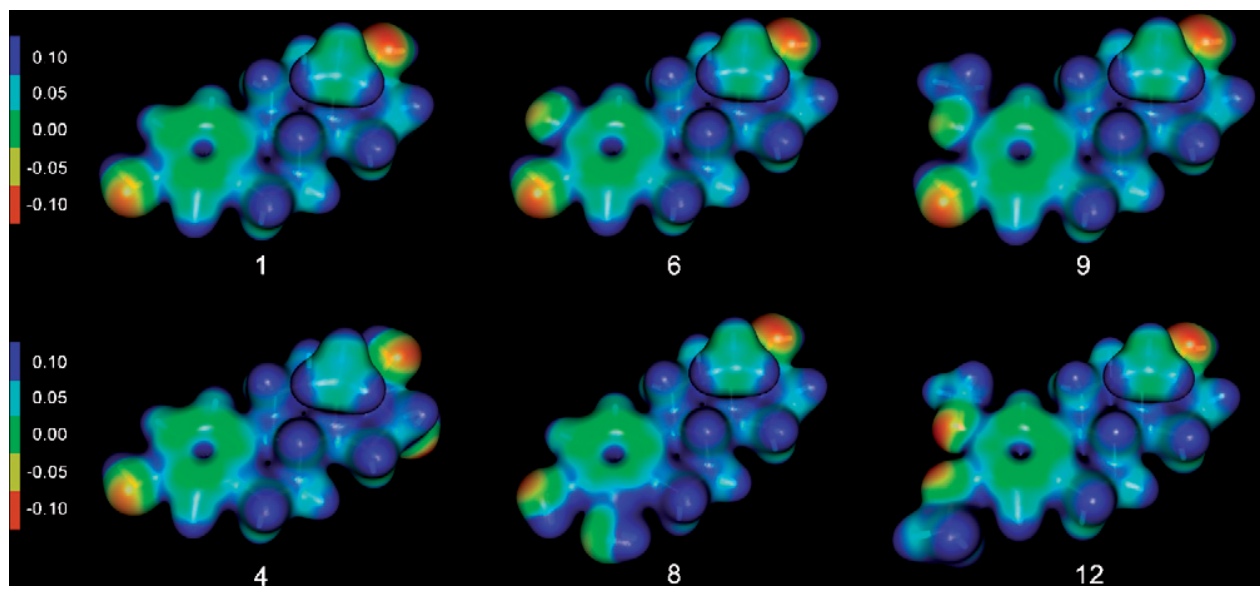

Fig. 4. Electrostatic surface potential (ESP) mapped on the $0.02 \mathrm{e} / \mathrm{A}^{3}$ electron density isocontour derived from ab initio $\mathrm{HF} / 6-31 \mathrm{G}^{*}$ calculations. $\mathrm{E}_{2}$ (1), $\mathrm{E}_{3}$ (4), $2-\mathrm{OHE}_{2}(\mathbf{6}), 4-\mathrm{OHE}_{2}(\mathbf{8}), 2-\mathrm{MeOE}_{2}(\mathbf{9})$ and $2-\mathrm{MeOE}_{2}, 3 \mathrm{Me}(\mathbf{1 2})$ are displayed from the $\beta$-face as shown by the transparent capped-stick model on the inside of the electron density contour. ESP ranges from $V=0.1 \mathrm{eV}$ (blue) to $V=-0.1 \mathrm{eV}$ (red). 


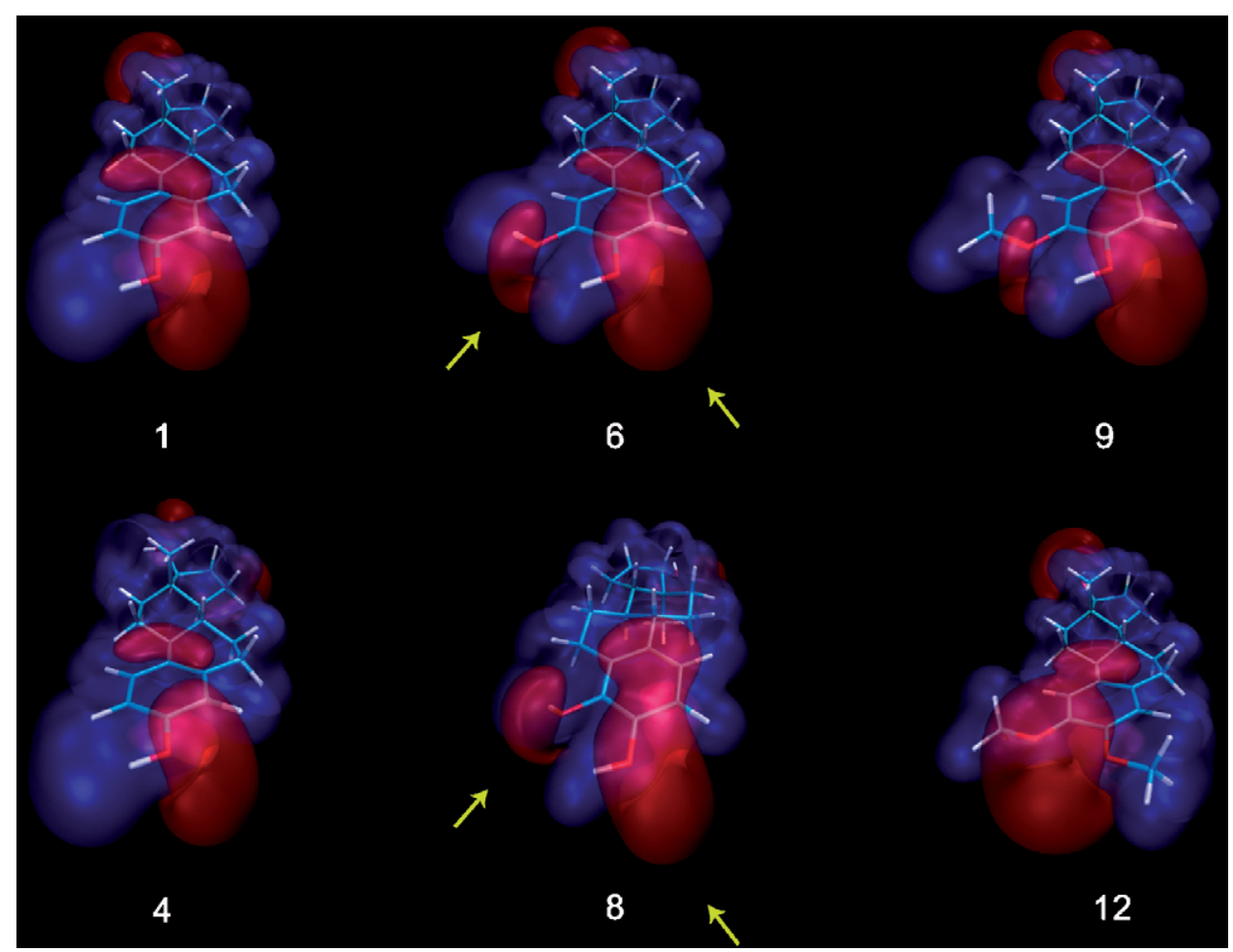

Fig. 5. Electrostatic surface potential derived from ab initio $\mathrm{HF} / 6-31 \mathrm{G}^{*}$ calculations at isosurface values of $V=0.025 \mathrm{eV}$ (blue) and $V=-0.025 \mathrm{eV}$ (red). $\mathrm{E}_{2}$ (1), $\mathrm{E}_{3}(\mathbf{4}), 2-\mathrm{OHE}_{2}(\mathbf{6}), 2-\mathrm{MeOE}_{2}(\mathbf{9})$ and 2-MeOE, $3 \mathrm{Me}(\mathbf{1 2})$ are displayed from the $\beta$-face as shown by the transparent capped-stick model on the inside of the ESP contour. $4-\mathrm{OHE}_{2}(\mathbf{8})$ is displayed from the $\alpha$-face. Arrows indicate similarities in the negative potential contour of the most active compounds.

anti-aromatase potency. Moreover, the $16 \alpha$-hydroxylation, leads to weak aromatase inhibitors with only $8-9 \%$ inhibition at a $100 \mu \mathrm{M}$ concentration, as seen for $\mathrm{E}_{3}(\mathbf{4})$ and $16 \alpha-\mathrm{OHE}_{1}(\mathbf{3})$.

In particular, the anti-aromatase activity of $2-\mathrm{OHE}_{2}(\mathbf{6})$, the most potent inhibitor tested, was found to be ca. 200 times stronger than $\mathrm{E}_{2}$ (1). This molecule competed with androstenedione for the active site of the enzyme showing a typical competitive Lineweaver-Burk plot (Fig. 3) and a good relative potency of aromatase inhibition $\left(K_{\mathrm{i}} / K_{\mathrm{m}}=11\right)$. These results are in agreement with the type of inhibition found for estradiol and estrone [18] and demonstrate for the first time that estrogens metabolized to catechol derivatives have an increased anti-aromatase potential.

Steric and electronic effects are expected to control the recognition and binding affinity of these molecules to the active site of aromatase. Catechol estrogens have in common a pair of hydroxyl groups prone to interact with the aromatase active site, either at $\mathrm{C} 2$ and $\mathrm{C} 3$, in compounds 5 and $\mathbf{6}$ or at $\mathrm{C} 3$ and $\mathrm{C} 4$ in compounds $\mathbf{7}$ and $\mathbf{8}$. Large differences in anti-aromatase potency between catechols and the other estrogens in study suggest that catechol hydroxyls are involved in strong electrostatic interactions, like hydrogen bonds, either as donors or as acceptors, or in coordination with the heme iron at the aromatase active site. Methoxylation of one or both Aring hydroxyl groups strongly blocks the accessibility to the enzyme and prevents the establishment of favorable interactions. No relationships between anti-aromatase activity and the oxidation state at C-17, either hydroxyl or ketone, were found.
Human breast tissue is a major source of estrogen production in post-menopausal women. Breast cells contain steroidogenic enzymes essential to estrogen production, as well as estrogen metabolizing enzymes [25-27]. $2-\mathrm{OHE}_{2}(\mathbf{6})$ is produced mainly by CYP1A1, CYP1A2 and CYP3A4, whereas $4-\mathrm{OHE}_{2}(\mathbf{8})$ is produced mostly by the CYP1B1 [28]. Genetic polymorphisms of several estrogen metabolizing enzymes have been identified [29]. Different variant alleles of CYP1A1 and CYP1B1 determine changes in the ratio of 2-/4-hydroxy formation and these differences have been correlated with post-menopausal breast cancer risk [27]. In particular, catechol estrogens seem to play a dual role on the initiation of breast tumors: while 2-hydroxy derivatives have preventive effect due to their anti-estrogenic and antiproliferative activities in hormone-dependent human breast cancer cells [9,30], 4-hydroxy derivatives may act as tumor initiators due to a significative estrogenic activity [6] and the formation of 3,4-quinones, electrophilic intermediates that covalently bind to DNA and form depurinating adducts [31,32].

Although plasma levels of estrogen metabolites are low, these concentrations do not reflect the local concentrations. Indeed, high levels of catechol estrogens were detected in both normal and breast cancer tissue samples. Castagnetta et al. [33] reported a concentration of catechol estrogens 50 times higher than those of E1 and E2, suggesting that oxidative metabolism in the breast tissue is very effective. On the other hand, androstenedione concentration in tumor breast tissue was found to be ca. 10 times greater than the estradiol levels [34,35]. Therefore, catechol concentrations might be greater than the levels of androgens, competing to the active site of the aromatase. 
COMT is the major enzyme in catechol biotransformation. Kinetic analysis of this enzyme in the presence of catechol estrogens, has revealed higher catalytic efficiency for the formation of C4-methoxy estrogens than C2-methoxy estrogens and $K_{\mathrm{m}}$ values are the range of 24-108 $\mu \mathrm{M}$ [36]. Considering these data and the low $K_{\mathrm{i}}(1.6 \mu \mathrm{M})$ found by us for $2-\mathrm{OHE} 2(\mathbf{6})$, we can speculate that estrogens are stable enough to inhibit the aromatase enzyme. Thus, the results of our study suggest that the oxidative metabolism of estrogens in the breast might be responsible for an intracrine control mechanism of the aromatase activity exerted by catechol estrogens. In particular the $2-\mathrm{OHE}_{2}$ (6) which is non carcinogenic in vivo and almost devoid of estrogenic activity [6], might offer protection against excessive production of estrogens in post-menopausal women, and consequently against breast cancer. So, the effectiveness of this mechanism of competitive inhibition will depend on the in situ concentrations of estrogen catechols and androgens, and on the metabolic stability of the catechols.

Moreover, the strongest anti-aromatase activity found in the present work for the 2-OHE 2 (6), suggests that a shift towards the 2-hydroxylation pathway might determine some long-term protection against breast cancer by a biochemical mechanism of competitive inhibition of the enzyme aromatase. Furthermore, $2-\mathrm{MeOE}_{2}(\mathbf{9})$, the product of $2-\mathrm{OHE}_{2}(\mathbf{6})$, methoxylation by COMT is a potent antiangiogenic and antiproliferative compound, already in clinical trials [10].

The reduced oral bioavailability of catechol estrogens due to methylation by COMT and the potential to undergo metabolic redox cycling with generation of free radicals and reactive semiquinone/quinone derivatives limits the use of catechol estrogens as therapeutical agents to the endocrine treatment of breast cancer. Further studies based on the chemical physical results obtained here should therefore be performed in order to find appropriate bioisosteric derivatives, devoid of estrogenic activity or having anti-estrogenic activity, with improved pharmacokinetics and reduced toxicity.

In summary, we have demonstrated that natural catechol estrogens have strong anti-aromatase activity and might be responsible for an intracrine control mechanism of estrogen production in post-menopausal women. With our study, important molecular recognition determinants have been calculated and from this integrated approach, structure-activity rules have been rationalized which can be used for the lead optimization of new aromatase inhibitors.

\section{Acknowledgments}

Thanks are due to Fundação para a Ciência e a Tecnologia (FCT) through POCTI (FEDER) for financial support. We also thank the Maternity Daniel de Matos, Coimbra, Portugal for kindly provide the human placenta. M.A.C. Neves thanks Dr. M. Meli and Dr. G.M.S. de Mori for help on the computational methods, and FCT for a Ph.D. grant (SFRH/BD/17624/2004).

\section{References}

[1] M.Y. Farhat, M.C. Lavigne, P.W. Ramwell, The vascular protective effects of estrogen, FASEB J. 10 (1996) 615-624.
[2] B.L. Riggs, S. Khosla, L.J. Melton, Sex steroids and the construction and conservation of the adult skeleton, Endocr. Rev. 23 (2002) 279-302.

[3] L.M. Garcia-Segura, I. Azcoitia, L.L. DonCarlos, Neuroprotection by estradiol, Prog. Neurobiol. 63 (2001) 29-60.

[4] B.E. Henderson, H.S. Feigelson, Hormonal carcinogenesis, Carcinogenesis 21 (2000) 427-433

[5] B.T. Zhu, A.H. Conney, Functional role of estrogen metabolism in target cells: review and perspectives, Carcinogenesis 19 (1998) 1-27.

[6] N. Schutze, G. Vollmer, I. Tiemann, M. Geiger, R. Knuppen, Catecholestrogens Are Mcf-7 cell estrogen-receptor agonists, J. Steroid Biochem. Mol. Biol. 46 (1993) 781-789.

[7] L.M. Nutter, E.O. Ngo, Y.J. Abulhajj, Characterization of DNA damage induced by 3,4-estrone-ortho-quinone in human-cells, J. Biol. Chem. 266 (1991) 16380-16386.

[8] J.G. Liehr, W.F. Fang, D.A. Sirbasku, A. Ariulubelen, Carcinogenicity of catechol estrogens in Syrian-Hamsters, J. Steroid Biochem. Mol. Biol. 24 (1986) 353-356.

[9] J. Schneider, M.M. Huh, H.L. Bradlow, J. Fishman, Antiestrogen action of 2-hydroxyestrone on Mcf-7 human-breast cancer-cells, J. Biol. Chem. 259 (1984) 4840-4845.

[10] T. Fotsis, Y. Zhang, M.S. Pepper, H. Adlercreutz, R. Montesano, P.P. Nawroth, L. Schweigerer, The endogenous oestrogen metabolite 2methoxyoestradiol inhibits angiogenesis and suppresses tumour growth, Nature 368 (1994) 237-239.

[11] G.E. Swaneck, J. Fishman, Covalent binding of the endogenous estrogen 16-alpha-hydroxyestrone to estradiol-receptor in human-breast cancercells - characterization and intranuclear localization, Proc. Natl. Acad. Sci. U.S.A. 85 (1988) 7831-7835.

[12] G.C. Kabat, C.J. Chang, J.A. Sparano, D.W. Sepkovic, X.P. Hu, A. Khalil, R. Rosenblatt, H.L. Bradlow, Urinary estrogen metabolites and breast cancer: a case-control study, Cancer Epidemiol. Biomarkers Prev. 6 (1997) 505-509.

[13] J. Schneider, D. Kinne, A. Fracchia, V. Pierce, K.E. Anderson, H.L. Bradlow, J. Fishman, Abnormal oxidative-metabolism of estradiol in women with breast-cancer, Proc. Natl. Acad. Sci. U.S.A. 79 (1982) 3047-3051.

[14] E.A. Thompson, P.K. Siiteri, Involvement of human placental microsomal cytochrome-P-450 in aromatization, J. Biol. Chem. 249 (1974) 5373-5378.

[15] A.R.W. Forrest, Aromatase inhibitors in breast cancer, N. Engl. J. Med. 349 (2003) 1090

[16] M. Baum, A.U. Buzdar, J. Cuzick, J. Forbes, J. Houghton, J.G.M. Klijn, T. Sahmoud, Anastrozole alone or in combination with tamoxifen versus tamoxifen alone for adjuvant treatment of postmenopausal women with early breast cancer: first results of the ATAC randomised trial, Lancet 359 (2002) 2131-2139.

[17] H. Mouridsen, M. Gershanovich, Y. Sun, R. Perez-Carrion, C. Boni, A. Monnier, J. Apffelstaedt, R. Smith, H.P. Sleeboom, F. Janicke, A. Pluzanska, M. Dank, D. Becquart, P.P. Bapsy, E. Salminen, R. Snyder, M. Lassus, J.A. Verbeek, B. Staffler, H.A. Chaudri-Ross, M. Dugan, Superior efficacy of letrozole versus tamoxifen as first-line therapy for postmenopausal women with advanced breast cancer: results of a phase III study of the international letrozole breast cancer group, J. Clin. Oncol. 19 (2001) 2596-2606.

[18] Y. Shimizu, C. Yarborough, Y. Osawa, Competitive product inhibition of aromatase by natural estrogens, J. Steroid Biochem. Mol. Biol. 44 (1993) 651-656.

[19] K.J. Ryan, Biological aromatization of steroids, J. Biol. Chem. 234 (1959) 268-272.

[20] P.K. Siiteri, E.A. Thompson, Studies of human placental aromatase, J. Steroid Biochem. Mol. Biol. 6 (1975) 317-322.

[21] J.M. Goodman, W.C. Still, An unbounded systematic search of conformational space, J. Comput. Chem. 12 (1991) 1110-1117.

[22] T.A. Halgren, Merck molecular force field, J. Comput. Chem. 17 (1996) 490-519.

[23] W.C. Still, A. Tempczyk, R.C. Hawley, Thomas Hendrickson, semianalytical treatment of solvation for molecular mechanics and dynamics, J. Am. Chem. Soc. 112 (1990) 6127-6129.

[24] M.J. Frisch, G.W. Trucks, H.B. Schlegel, G.E. Scuseria, M.A. Robb, J.R. Cheeseman, V.G. Zakrzewski, J.A. Montgomery Jr., R.E. Stratmann, J.C. Burant, S. Dapprich, J.M. Millam, A.D. Daniels, K.N. Kudin, M.C. Strain, 
O. Farkas, J. Tomasi, V. Barone, M. Cossi, R. Cammi, B. Mennucci, C. Pomelli, C. Adamo, S. Clifford, J. Ochterski, G.A. Petersson, P.Y. Ayala, Q. Cui, K. Morokuma, D.K. Malick, A.D. Rabuck, K. Raghavachari, J.B. Foresman, J. Cioslowski, J.V. Ortiz, A.G. Baboul, B.B. Stefanov, G. Liu, A. Liashenko, P. Piskorz, I. Komaromi, R. Gomperts, R.L. Martin, D.J. Fox, T. Keith, M.A. Al-Laham, C.Y. Peng, A. Nanayakkara, C. Gonzalez, M. Challacombe, P.M.W. Gill, B.G. Johnson, W. Chen, M.W. Wong, J.L. Andres, M. Head-Gordon, E.S. Replogle, J.A. Pople, Gaussian 98 (Revision A.7), Gaussian, Inc., Pittsburgh, PA, 1998.

[25] L.M. Berstein, A.A. Larionov, A.S. Kyshtoobaeva, K.M. Pozharisski, V.F. Semiglazov, O.A. Ivanova, Aromatase in breast cancer tissue-localization and relationship with reproductive status of patients, J. Cancer Res. Clin. Oncol. 122 (1996) 495-498.

[26] F. Labrie, V. Luu-The, C. Labrie, A. Belanger, J. Simard, S.X. Lin, G. Pelletier, Endocrine and intracrine sources of androgens in women: inhibition of breast cancer and other roles of androgens and their precursor dehydroepiandrosterone, Endocr. Rev. 24 (2003) 152 182.

[27] J.G. Liehr, M.J. Ricci, 4-Hydroxylation of estrogens as marker of human mammary tumors, Proc. Natl. Acad. Sci. U.S.A. 93 (1996) 32943296.

[28] A.J. Lee, M.X.X. Cai, P.E. Thomas, A.H. Conney, B.T. Zhu, Characterization of the oxidative metabolites of 17 beta-estradiol and estrone formed by 15 selectively expressed human cytochrome $\mathrm{P} 450$ isoforms, Endocrinology 144 (2003) 3382-3398.

[29] Y. Tsuchiya, M. Nakajima, T. Yokoi, Cytochrome P450-mediated metabolism of estrogens and its regulation in human, Cancer Lett. 227 (2005) 115-124.
[30] H. Seeger, J. Huober, D. Wallwiener, A.O. Mueck, Inhibition of human breast cancer cell proliferation with estradiol metabolites is as effective as with tamoxifen, Horm. Metab. Res. 36 (2004) 277-280.

[31] E. Cavalieri, D. Chakravarti, J. Guttenplan, E. Hart, J. Ingle, R. Jankowiak, P. Muti, E. Rogan, J. Russo, R. Santen, T. Sutter, Catechol estrogen quinones as initiators of breast and other human cancers: implications for biomarkers of susceptibility and cancer prevention, Biochim. Biophys. Acta 1766 (2006) 63-78.

[32] P. Devanesan, R.J. Santen, W.P. Bocchinfuso, K.S. Korach, E.G. Rogan, E. Cavalieri, Catechol estrogen metabolites and conjugates in mammary tumors and hyperplastic tissue from estrogen receptor-alpha knock-out (ERKO)/Wnt-1 mice: implications for initiation of mammary tumors, Carcinogenesis 22 (2001) 1573-1576.

[33] L.A. Castagnetta, O.M. Granata, A. Traina, B. Ravazzolo, M. Amoroso, M. Miele, V. Bellavia, B. Agostara, G. Carruba, Tissue content of hydroxyestrogens in relation to survival of breast cancer patients, Clin. Cancer Res. 8 (2002) 3146-3155.

[34] M.A. Blankenstein, I. Maitimu-Smeele, G.H. Donker, J. Daroszewski, A. Milewicz, J.H. Thijssen, Tissue androgens and the endocrine autonomy of breast cancer, J. Steroid Biochem. Mol. Biol. 43 (1992) 167-171.

[35] M.A. Blankenstein, I. Maitimu-Smeele, G.H. Donker, J. Daroszewski, A. Milewicz, J.H. Thijssen, On the significance of in situ production of oestrogens in human breast cancer tissue, J. Steroid Biochem. Mol. Biol. 41 (1992) 891-896.

[36] S. Dawling, N. Roodi, R.L. Mernaugh, X. Wang, F.F. Parl, Catechol-Omethyltransferase (COMT)-mediated metabolism of catechol estrogens: comparison of wild-type and variant COMT isoforms, Cancer Res. 61 (2001) 6716-6722. 